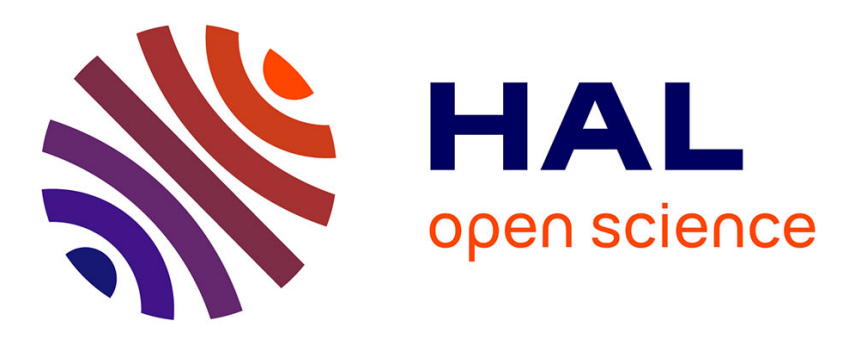

\title{
An optimization approach for MPS in a MTO multiproduct assembly line system
}

Estefania Tobon Valencia, Seyed-Esmaeil Moussavi, Samir Lamouri, Robert Pellerin, Alexandre Moeuf

\section{- To cite this version:}

Estefania Tobon Valencia, Seyed-Esmaeil Moussavi, Samir Lamouri, Robert Pellerin, Alexandre Moeuf. An optimization approach for MPS in a MTO multiproduct assembly line system. 8th International Conference on Industrial Engineering and Systems Management, Sep 2019, Shanghai, China. 10.1109/IESM45758.2019.8948090 . hal-02475781

\section{HAL Id: hal-02475781 \\ https://hal.science/hal-02475781}

Submitted on 12 Feb 2020

HAL is a multi-disciplinary open access archive for the deposit and dissemination of scientific research documents, whether they are published or not. The documents may come from teaching and research institutions in France or abroad, or from public or private research centers.
L'archive ouverte pluridisciplinaire HAL, est destinée au dépôt et à la diffusion de documents scientifiques de niveau recherche, publiés ou non, émanant des établissements d'enseignement et de recherche français ou étrangers, des laboratoires publics ou privés. 


\section{An optimization approach for MPS in a MTO multiproduct assembly line system}

\author{
Estefania Tobon Valencia \\ LAMIH \\ Arts et Métiers Paristech \\ Paris, France \\ estefania.tobon-valenica $(a)$ ensam.eu
}

\author{
Seyed-Esmaeil Moussavi \\ ELLIADD \\ Universitde Technologie de \\ Belfort-Montbeliard \\ Montbéliard, France
}

seyed-esmaeil.moussavi@utbm.fr

\author{
Samir Lamouri \\ LAMIH \\ Arts et Métiers Paristech \\ Paris, France \\ Samir.lamouri $a$ ensam.eu
}

\author{
Robert Pellerin \\ Mathematics and Industrail \\ Engineering Department \\ Polytechnique Montreal \\ Quebec,Canada \\ robert.pellerin $a$ polymtl.ca
}

\author{
Alexandre Moeuf \\ Exxelia Technologies \\ Chanteloup-en-Brie, France \\ alexandre.moeuf $a$ exxelia.com
}

\begin{abstract}
The paper presents a preliminary version of a decision-making tool for tactical planning in a Make-To-Order (MTO) multi-product, multiple-assembly line SME (Small and Medium-Sized Enterprises) environment with heterogeneous workers. A single objective mixed-integer mathematical model is proposed to identify quantities of finished products to be produced in different planning horizons while respecting capacity availability. The main objective of the model is to minimize the tardiness in delivery of customer orders. The proposed model was tested with nine instances. The computational results prove the capability of the proposed model to reduce delay on deliveries.
\end{abstract}

Keywords - MPS, SME, production planning, multiproduct, make- to-order, scheduling

\section{INTRODUCTION}

Production planning activities aim to define what is going to be produced, the required resources and materials to produce it, the date when they are needed and resource availability. These activities can be grouped in different planning levels according to the objectives, the planning horizon, the level of detail and the planning cycle [4]. Those levels include the strategic business plan, the sales and operations plan, the master production schedule, the material requirements plan, and purchasing and production activity control.

On a tactical level, the Master Product Schedule (MPS) is a program containing what an enterprise plans to produce by finished product, quantities and dates. This schedule considers data from the sales forecast, the production plan, raw material availability, available capacity, inventory levels and backlog [2]. The main objectives of MPS are to maintain the desired level of customer service, to make the best use of capacity and to keep inventories at a desired level [3].

In order to achieve the before-mentioned objectives, decisions on items such as working extra hours, increasing resources, day shifting customer orders, splitting delivery quantities and advancing the production of a customer's order, are made.

Respecting delivery dates is an important objective to maintain a desired level of customer service. In this paper we present an optimization approach to reduce tardiness in delivery in a multi-product, multiple-assembly line in a SME context. For this purpose, we present a mathematical model for supporting decision-making at the MPS planning level.

Different models have been proposed for similar objectives, but they are focused on short-term planning decisions. For example, a mixed model for sequencing and scheduling with three objectives maximizing net profit, leveling material use and reducing sequence dependency setup time for an Assemble-To-Order (ATO) production system was proposed by Wang et al.[13].The authors employed a hybrid artificial bee colony algorithm solution approach. In an ATO power train manufacturing system, Lalami et al. used a MILP approach looking for satisfying customer demand, while minimizing safety stocks and balancing production load [7].

Mourtzis and Vlachou presented a multi-criteria model for real-time shop floor scheduling and condition based maintenance was proposed for a multiproduct, single assembly line for a mould-making SME [9]. For similar production conditions, Buyurgan and Saygin built a simulation environment, to validate a model for real time scheduling and part rooting [5].

Dörmer et al. introduced a mathematical model for minimizing the workload variability using a heuristic solution approach [6]. A genetic algorithm was employed by $\mathrm{Li}$ and $\mathrm{He}$ in order to optimize scheduling while improving payment and profit in a mixed-model assembly line [8]. Scheduling optimization was also one of the objectives of the mathematical approach that Vallhagen et al. proposed for a multi-product, single assembly line [12].

Considering an MPS application, Akhoondi and Lotfi presented a mathematical model for minimizing planning cost, which was calculated based on the production, backorder and carrying costs [1]. In an MTO environment, the proposition of Sawik looks for minimizing tardiness in a flow-shop system while minimizing the input and output inventories and leveling the aggregate production [11]. The work of Sahin et al., which was also addressed for an MTO system, aimed to optimize the scheduling cost and stability [10].

The originality of the proposed model in comparison with the before-mentioned propositions comes from one side from 
the manufacturing environment, which is a Make-to-Order, multi-assembly line in an SME. In addition, each assembly line produces various finished products. Hence, the studied system is considered multiproduct. Furthermore, a consideration of the lot sizing constraint in the mathematical model, the model validation through real instances and the use of results in an MPS logic are part of the model's originality.

The model was programmed with the GMPL mathematical modeling language and solved by GLPK and GUROBI solvers using a mixed-integer linear programming (MILP) approach. A validation test program has been proposed and allowed to illustrate the efficiency of our proposed optimization approach.

The remainder of this paper is organized as follows: in section II we describe the proposed problem. In section III, the mathematical model is presented. The numerical application and results are presented in section IV. Finally, our conclusions, research perspectives and limitations are described in section $\mathrm{V}$.

\section{PROBLEM DESCRIPTION}

The model is intended to be used as a support tool for decision-making at the MPS level for the production line of a manufacturer and designer of complex passive components and precision systems. Around 430 products are produced in this production line. The site works under a make to order (MTO) production logic and there is no stock of finished products. Orders are processed in batches. Thus, only one order is processed by a workstation at any time. The production process is mainly artisanal, thus $90 \%$ of the operations are done by the production staff.

The produced goods in the line are divided into three macro-categories. For this study, they are named A, B and C. Each category requires different workstations. A workstation is defined by a set of operations and a group of workers.

For each product category, the workstations that are considered as potential bottlenecks were studied. Seven workstations per product macro-categories were considered as potential bottlenecks. Only products $\mathrm{A}$ and $\mathrm{C}$ are processed in the same workstations. Each workstation has a specific capacity, which is defined by three parameters: processing and set-up time, the number of available workers per workstation and the efficiency factor per worker. The group of workers is considered to be heterogeneous as each worker has different efficiency factors, according to the experience and the availability to perform tasks. Efficiency factors are defined and updated by the production, process and engineering managers monthly

Currently the MPS meetings are prepared by the Master Planner based on customized tools built in Excel using data extracted from the ERP system. In order to achieve one of the main objectives of the MPS, preserving the desired level of customer service, the proposed model has to provide the Master Planner means to analyze different production scenarios in order to minimize lateness in delivery of customer orders while balancing load and capacity in the production assembly lines.

Nevertheless, in order to be able to model mathematically the before mentioned problem the following assumptions have been considered:
- All the required raw material for producing an order are a $100 \%$ available before the beginning of the production,

- All the production staff is available in every working day of the planning horizon.

- Inventory-penalty cost for orders that are finished earlier is not considered, as part of the study as there are arrangements between the enterprise and the customer to advance delivery.

\section{MILP-MATHEMATICAL MODEL}

In order to minimize the tardiness of a delivery, a mathematical model with a single objective function is proposed based on a mixed-integer linear programming (MILP) approach. The proposed mathematical model has been programmed in the GMLP mathematical programming language and was solved using GUROBI solver. A detailed description of the parameters and variables is defined in the following subsection. Then, the model formulation containing the objective function and the constraints are presented.

\section{A. Indices, parameters and variables}

Five groups of indices are used in the proposed model: products ( $\mathrm{i}$ and $\mathrm{p}$ ), customer orders (j), periods (t) workstations (k) and workers (r). These indices are used to describe the parameters and variables of the model.

The parameters of the model are the input data that are collected from the real manufacturing environment. The following list presents the parameters of our model:

$\mathrm{m}$ : Number of product types to be produced;

$\mathrm{n}$ : Number of customer orders to be delivered;

1: Number of workstations needed to produce the ordered products;

$\mathrm{d}$ : Length of the planning horizon, presented by number of days;

s: Number of operators working in the studied production line;

$\mathrm{H}$ : Number of working minutes per day for the operators and machines.

$\mathrm{D}$ : Deadline for delivering customer order $j$;

$\mathrm{Q}_{\mathrm{ij}}$ : Quantity of product $i$ asked by order $j$;

$\mathrm{P}_{\mathrm{ik}}$ : Processing time needed to produce one product of type $i$ in workstation $k$;

$\mathrm{A}_{\mathrm{ik}}$ : Set-up time needed to produce the products of type $i$ in workstation $k$;

\section{$\mathrm{E}_{\text {. }}$ : Efficiency of operator $r$ in workstation $k$;}

$\mathrm{M}_{\mathrm{k}}$ : Maximum number of workers that can be assigned to workstation $k$ during a working day;

BM: a very big number. 
The model variables give the user the output data that will be exploited to prepare MPS meetings. The results of the model are subject to a set of decision variables represented in our model as $x_{i j t}$, that represents the quantity of product $i$ demanded by customer order $j$ that is produced on day $t$. The other variables of the model are defined as follows:

$\mathrm{y}_{\mathrm{j} j \mathrm{t}}$ : Binary variables equal to 1 , if the product $\mathrm{i}$ of order $\mathrm{j}$ is produced on day $t$; Otherwise equal to 0 ,

$\mathrm{l}_{\mathrm{j}}$ : Lateness related to the delivery time of order $\mathrm{j}$, presented by number of days,

$v_{k i}$ : Capacity or availability of workstation $k$ on day $t$, presented by number of minutes,

$s_{i j k x}$ : Start time for operating a lot of product $\mathrm{i}$ related to order $\mathrm{j}$ in workstation $\mathrm{k}$ on day $\mathrm{t}$,

$\mathrm{f}_{\mathrm{ijk} k \mathrm{t}}$ : End time of the operation of a lot of product $\mathrm{i}$ related to order $\mathbf{j}$ in workstation $\mathrm{k}$ on day $\mathrm{t}$, indicating the last minute of the production of product $\mathrm{i}$ of order $\mathrm{j}$ in workstation $\mathrm{k}$ in the day $\mathrm{t}$,

$c_{j}$ : completion time of order $\mathrm{j}$, indicating the last day of the production of order $\mathrm{j}$,

$\mathrm{w}_{\mathrm{rkt}}$ : Binary variables presenting whether operator $\mathrm{r}$ is assigned to workstation $\mathrm{k}$ on day $\mathrm{t}$, or not,

$b p_{i p j k t}$ : Sequencing binary variables where $b p_{i p j k t}=1$. if product $\mathrm{i}$ of order $\mathrm{j}$ is processed before product $\mathrm{p}$ in workstation $\mathrm{k}$ on day $\mathrm{t}$; And $\mathrm{bp}_{\mathrm{ipjkt}}=0$, otherwise.

$Z$ : cumulated lateness for the customer order in the studied planning period.

\section{B. Objective function}

Lateness minimization, as the targeted objective, is represented by the function

$$
\text { Minimize } Z=\sum_{j \in J} l_{j}
$$

The objective function aims to reduce, as much as possible, the sum of the lateness for the set of customer orders to be delivered in the planning horizon.

\section{Constraints}

The solution must deal with the following constraints: demand, load balancing and sequencing. The demand constraints impose the production of the requested quantity by the customer for the demanded date or a minimal lateness inside the planning horizon. Load balancing constraints limit the use of resources to the available capacity. Finally, sequencing constraints indicate the order of products to be processed in each workstation by day as well as the starting and ending time per produced unit inside each workstation.

$$
\begin{aligned}
& \text { Demand Constraints } \\
& \qquad \sum_{\mathrm{t} \in \mathrm{T}} \mathrm{x}_{\mathrm{ij} \mathrm{t}}=\mathrm{Q}_{\mathrm{i} j} \forall \mathrm{i} \in \mathrm{I}, \mathrm{j} \in \mathrm{J} \\
& \mathrm{y}_{\mathrm{ijt}} \leq \mathrm{x}_{\mathrm{j} \mathrm{j}} \forall \mathrm{i} \in \mathrm{I}, \mathrm{j} \in \mathrm{J}, \mathrm{t} \in \mathrm{H} \\
& \text { BM } \times \mathrm{y}_{\mathrm{it} \mathrm{t}} \geq \mathrm{x}_{\mathrm{ijt}} \forall \mathrm{i} \in \mathrm{I}, \mathrm{j} \in \mathrm{J}, \mathrm{t} \in \mathrm{H}
\end{aligned}
$$

$$
\begin{aligned}
& \mathrm{c}_{\mathrm{i}}=\max _{\mathrm{it}}\left\{\mathrm{t} \times \mathrm{y}_{\mathrm{i}, \mathrm{t}}\right\} \quad \forall \mathrm{j} \in \mathrm{J} \\
& \mathrm{c}_{\mathrm{j}} \leq \mathrm{D}_{\mathrm{j}}+l_{\mathrm{j}} \quad \forall \mathrm{j} \in \mathrm{J}
\end{aligned}
$$

Constraint (2) ensures the production of the total customer demand of finished products for each customer order during the planning period.

The problem requires introducing a binary decision variable related to $X$ variable which is an integer. When $X$ equals zero, the binary $y$ takes a zero value. For values of $X$ greater than zero, the binary y always equals 1 . Constraints (3) and (4) entail a relation between our integer decision variable $\mathrm{X}$ and the binary decision variable $\mathrm{y}$.

Constraint (5) indicates the last day of the production of order $\mathrm{j}$. The product of $t$ and $\mathrm{y}_{\mathrm{ijt}}$ calculates the day in which production was carried. Then $\mathrm{c}$ takes the maximum value of this product. This constraint is not linear, and it has been linearized as follows in our linear mathematical model:

$$
\mathrm{c}_{\mathrm{j}} \geq \mathrm{t} \times \mathrm{y}_{\mathrm{ijt}} \forall \mathrm{i} \in \mathrm{I}, \mathrm{j} \in \mathrm{J}, \mathrm{t} \in \mathrm{T}
$$

Lastly, equation (6) determines the value of lateness for each customer order when the completion time is greater than the deadline. This constraint is the linearization of the following non-linear expression: if the completion time is greater than the deadline,then lateness is calculated as the difference between the completion time and the deadline.

$$
\begin{aligned}
& \text { Workstation Constraints } \\
& \begin{array}{l}
\mathrm{V}_{\mathrm{kt}}=\sum_{\mathrm{r} \in \mathrm{R}} \mathrm{E}_{\mathrm{rk}} \times \mathrm{w}_{\mathrm{rkt}} \times \mathrm{H} \quad \forall \mathrm{k} \in \mathrm{K}, \mathrm{t} \in \mathrm{H} \\
\sum_{\mathrm{r} \in \mathrm{R}} \mathrm{W}_{\mathrm{rt} t} \leq \mathrm{M}_{\mathrm{k}} \quad \forall \mathrm{k} \in \mathrm{K}, \mathrm{t} \in \mathrm{H}
\end{array}
\end{aligned}
$$$$
\sum_{\mathrm{j} \in \mathrm{J}} \sum_{\mathrm{i} \in \mathrm{I}}\left(\mathrm{A}_{\mathrm{ik}} \times \mathrm{y}_{\mathrm{ijt}}+\mathrm{P}_{\mathrm{ik}} \times \mathrm{x}_{\mathrm{ijl}}\right) \leq \mathrm{V}_{\mathrm{kt}} \quad \forall \mathrm{k} \in \mathrm{K}, \mathrm{t} \in \mathrm{H}
$$

Equation (7) defines the capacity of each workstation per period considering the efficiency factor of each assigned worker on a daily basis.

Constraint (8) imposes the maximum number of workers that can be assigned for each workstation per working period.

Finally, constraint (9) limits the capacity utilization per workstation for each working period. The constraint considers, for each workstation, both set up and production times of assembled products in one working period.

$$
\begin{aligned}
& \text { Sequencing Constraints } \\
& \mathrm{f}_{\mathrm{ijk}}=\mathrm{s}_{\mathrm{i} k \mathrm{kt}}+\left(\mathrm{y}_{\mathrm{ijt}} \times \mathrm{A}_{\mathrm{uk}}+\mathrm{x}_{\mathrm{ijt}} \times \mathrm{P}_{\mathrm{u}}\right) \quad \forall \mathrm{i} \in \mathrm{I}, \mathrm{j} \in \mathrm{J}, \mathrm{k} \in \mathrm{K}, \mathrm{t} \in \mathrm{H} \\
& \mathrm{f}_{\mathrm{i}, \mathrm{j} \mathrm{t}} \leq \mathrm{s}_{\mathrm{u},(\mathrm{k}+1) \mathrm{t}} \forall \mathrm{i} \in \mathrm{I}, \mathrm{j} \in \mathrm{J}, \mathrm{k} \in \mathrm{K}^{-}, \mathrm{t} \in \mathrm{H}
\end{aligned}
$$

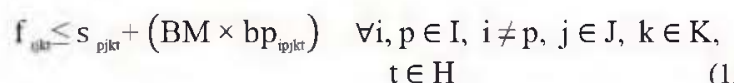

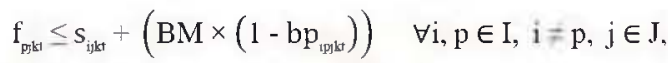

$$
\begin{aligned}
& k \in K, t \in H
\end{aligned}
$$




$$
\begin{gathered}
\mathrm{f}_{\mathfrak{t} \mathbf{k} 1} \leq \mathrm{h} \forall \mathrm{i} \in \mathrm{I}, \mathrm{j} \in \mathrm{J}, \mathrm{k} \in \mathrm{K}, \mathrm{t} \in \mathrm{H} \\
\mathrm{s}_{\mathrm{ijkt}} \leq \mathrm{h} \forall \mathrm{i} \in \mathrm{I}, \mathrm{j} \in \mathrm{J}, \mathrm{k} \in \mathrm{K}, \mathrm{t} \in \mathrm{H}
\end{gathered}
$$

Equation (10) computes the total production time per finished product of each customer order in every workstation and per working period. This time is calculated from the start set-up and operating times.

Constraint (11) indicates that the operation in a workstation begins only after the end of the last operation in the preceding workstation.

Equations (12) and (13) impose a sequencing constraint to the model. They prevent operations from overlapping over two different finished products inside a workstation at the same time. This means that they define the sequencing order between the products $\mathrm{i}$ and $\mathrm{p}$ in a workstation.

Constraints (14) and (15) guarantee that the starting and ending times in each workstation occur during the defined daily working period.

The before-mentioned model was validated by employing different size instances that were constructed with real data of the studied manufacturing system.

\section{NUMERICAL APPLICATION AND COMPUTATIONAL RESUltS}

The model presented in the previous section aims to minimize the lateness of delivery of customer orders through the definition of quantities to be produced per day in the planning horizon while balancing load and capacity in each workstation. As was mentioned in the problem description, the outputs of the mathematical solution are to be used as a decision support tool in the MPS meetings.

The model was validated with nine instances. Three groups of instances were defined for each product category, being: small, medium and large. These groups were defined based on the value of the parameters $m$ and $n$, that is the number of finished products to be produced and number of customer orders to be delivered. Small instances are related to a maximum of 4 customer orders $(n)$, medium instances are up to 10 customer orders and large instances are related to 20 customer orders. The value of the parameter number of finished products $(m)$ to be produced was similarly up to 4 and $\mathbf{1 0}$ for the small and medium instances and up to 19 for the large instance. All other instances were built by varying the model parameters. The number of workstations $(l)$ and the number of workers $(s)$ varied from 5 workstations and 6 workers for small instances and 6 workstations -7 workers in medium and large instances. For resources inside the workstations, machines and workers were considered in each instance.

Table I shows the value of the objective function cumulated lateness $(Z)$ for each couple instance size (column IS) and product category (column P). Columns C-T represent the computing time employed by the solver to propose the solution for each instance.

\begin{tabular}{|c|c|c|c|c|c|c|}
\hline & \multicolumn{2}{|c|}{$\begin{array}{c}\text { General } \\
\text { Parameters }\end{array}$} & \multicolumn{2}{|c|}{$\begin{array}{c}\text { Model } \\
\text { Parameters }\end{array}$} & \multicolumn{2}{|c|}{$\begin{array}{l}\text { Computing } \\
\text { Results }\end{array}$} \\
\hline $\begin{array}{c}\text { Instance } \\
\text { ID }\end{array}$ & IS & $\mathrm{P}$ & $\mathrm{Q}$ & $\bar{d}$ & $Z$ & C-T (s) \\
\hline 1 & \multirow{3}{*}{ Small } & $\mathrm{A}$ & 1650 & 11 & 24 & $<1$ \\
\hline 2 & & $B$ & 618 & 30 & 2 & 4.2 \\
\hline 3 & & $\mathrm{C}$ & 105 & 148 & 3 & $<1$ \\
\hline 4 & \multirow{3}{*}{ Medium } & $\mathrm{A}$ & 1806 & 18 & 2 & $<1$ \\
\hline 5 & & B & 2153 & 130 & 45 & 33.47 \\
\hline 6 & & $\mathrm{C}$ & 445 & 53 & 28 & 2 \\
\hline 7 & \multirow{3}{*}{ Large } & $\mathrm{A}$ & 3850 & 34 & 62 & 2312 \\
\hline 8 & & B & 3059 & 197 & 57 & 445 \\
\hline 9 & & $\mathrm{C}$ & 1124 & 190 & 2 & 5.88 \\
\hline
\end{tabular}

TABLE I- COMPUTATIONAL RESULTS

IS : Instance Size, P : Product Category, Q : Total Demanded Quantity, d: Planning Horizon, Z: Sum of Lateness, C-T: Computing Results in seconds

Differences in the values of the planning horizon for each product category are related to different lead times in both the procurement and production. The product category $\mathrm{B}$ presents a longer delay in production, while products in $\mathrm{C}$ have a longer procurement delay.

Results presented in Table I for all the groups of instances (small, medium and large) show that the total demand and the planning horizon have an influence on the value of the cumulated lateness $(Z)$. A big value of demand in a small planning horizon increases the cumulated lateness.

When analyzing results by product category, group B has the highest value of cumulated lateness for the three groups of instances. A mean of 35 days of cumulated lateness was calculated for this group versus a mean of 88 days of cumulated lateness for group A and 11 days for group $C$. The variation in the mean of lateness by product category can be explained through differences in operating times. In fact, operating times of the B product category are three times bigger than the value of this parameter for the two other product categories (A and C). Therefore, the related load for producing similar quantities of product type $B$ is considerably superior to the other two categories.

The computing time increases exponentially with a group of instances. The small instances present a mean of 4.2 seconds, medium instances of 17.73 seconds and large instances of about 15 minutes ( 920 seconds).

An analysis of the computing time for each product category ( $A, B$ and $C$ ) as a function of the number of scheduled orders (n) is presented in Fig. 1. Three demand sizes define each curve, being 4,10 and 20 customer orders.

The curve for the computing time of product category $\mathrm{A}$ is highly exponential. Product category B also presents a computing time that increases exponentially, but its tendency is lower than the one that showed product category A. Finally, the computing time curve for product category $\mathrm{C}$ is linear or slightly exponential. 
The study of computational times proves firstly that the studied combinatorial optimization problem is NP-hard. Secondly, this analysis shows that the proposed exact solution approach is very efficient for small and medium-size instances.

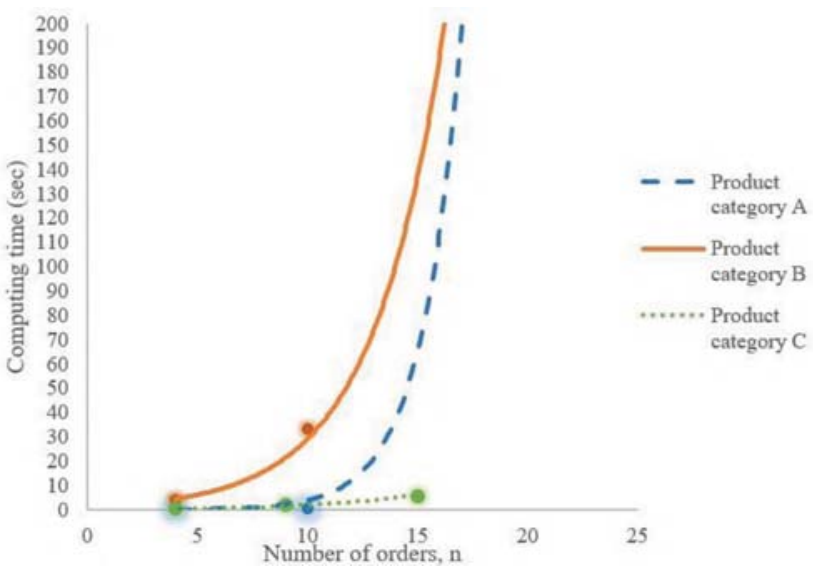

Fig. 1. Computing time per product category as a function of the scheduled group of orders

Table II presents a scope of the model's results for the first instance in the basis of an MPS model. In this instance the finished products $(w, x, y, z)$ shown in column $P$ are part of the product category A. Each finished product ordered by a customer is identified in column $(\mathrm{O})$. The demanded quantity is defined in column (Q).

The planning horizon defined for this instance was 11 working days. The working days are presented in rows 1 to 11 below the cell titled "Planning Horizon". For each customer order, three rows are defined in Table II. The " $q$ " line per product represents the requested quantity by the customer. This line serves as input data of the model. Two lines below this value, the "p" line shows the suggested quantity per finished product to be produced per day. The data in this line are outputs of the model. Finally, the "s" line of each item represents the available stock of finished products. The stock is calculated as the difference between the ordered and the produced quantities. At the end of the planning period, the stock of the finished product is zero for all the items. This is a common value when working under an MTO production strategy.
The value of the cumulated lateness, calculated by the model for each customer order is presented in Table II in the column Compt $Z$ (as computational Lateness) and it is presented in working days. In the following column, the actual lateness was extracted from the ERP system for each customer order

A performance indicator of the model's performance has been defined in column "Imp" (as improve). This indicator calculates the difference between the actual lateness and the model's lateness. A negative value in this column means that the customer order was delivered sooner than the proposed day by the model

For the first instance, only one order out of four was delivered on time and before the model predicted. The lateness for this instance was minimized with a mean of 48 labor days for three customer orders. These results allow the performance of the model propositions to be tested under the defined conditions of raw materials and capacity availability.

Further analysis showed that the main element causing differences between the actual and the calculated lateness is the unavailability of raw materials at the required date for the beginning of production. The results in the model could then be exploited to define the maximum arrival day of supplier orders to the production line. In fact, when the Master Schedule is properly updated, it can be used to drive material requirement planning and the production sequencing (APICS The Association for Operations Management, 2010).

One of the objectives of the MPS meetings is to define the quantity per finished product to be produced and the production dates. In order to do so, the load must be defined in the workstations considered as bottlenecks. Then, it is necessary to compare it with the available capacity. The identification of the over and under-load conditions will provide a basis to identify the adjustments of the quantities to be produced. The results presented in Table II constitute a support for analyzing the load-capacity condition per working day on the assembly line.

TABLE II- MPS BASIS FOR THE FIRST INSTANCE

\begin{tabular}{|c|c|c|c|c|c|c|c|c|c|c|c|c|c|c|c|c|c|}
\hline & & & & & & & \multicolumn{11}{|c|}{ Planning Horizon } \\
\hline $\mathrm{O}$ & $\mathrm{P}$ & $Q$ & Compt Z & Real Z & $\operatorname{Imp}$ & & 1 & 2 & 3 & 4 & 5 & 6 & 7 & 8 & 9 & 10 & 11 \\
\hline \multirow{3}{*}{1} & \multirow{3}{*}{ w } & \multirow{3}{*}{150} & \multirow{3}{*}{3} & \multirow{3}{*}{84} & \multirow{3}{*}{81} & $q$ & 150 & & & & & & & & & & \\
\hline & & & & & & $\mathrm{s}$ & -104 & -92 & -46 & 0 & & & & & & & \\
\hline & & & & & & $p$ & 46 & 12 & 46 & 46 & & & & & & & \\
\hline \multirow{3}{*}{2} & \multirow{3}{*}{$x$} & \multirow{3}{*}{500} & \multirow{3}{*}{8} & \multirow{3}{*}{0} & \multirow{3}{*}{-8} & $\mathrm{q}$ & & & 500 & & & & & & & & \\
\hline & & & & & & $\mathrm{s}$ & 46 & 86 & -368 & -322 & -276 & -230 & -184 & -138 & -92 & -46 & 0 \\
\hline & & & & & & $p$ & 46 & 40 & 46 & 46 & 46 & 46 & 46 & 46 & 46 & 46 & 46 \\
\hline \multirow{3}{*}{3} & \multirow{3}{*}{$\mathrm{y}$} & \multirow{3}{*}{500} & \multirow{3}{*}{7} & \multirow{3}{*}{55} & \multirow{3}{*}{48} & $\mathrm{q}$ & & & & & 500 & & & & & & \\
\hline & & & & & & $\mathrm{s}$ & 46 & 92 & 132 & 178 & -276 & -230 & -184 & -138 & -92 & -46 & 0 \\
\hline & & & & & & $p$ & 46 & 46 & 40 & 46 & 46 & 46 & 46 & 46 & 46 & 46 & 46 \\
\hline \multirow{3}{*}{4} & \multirow{3}{*}{$\mathrm{z}$} & \multirow{3}{*}{500} & \multirow{3}{*}{6} & \multirow{3}{*}{74} & \multirow{3}{*}{68} & $q$ & & & & 500 & & & & & & & \\
\hline & & & & & & $\mathrm{s}$ & 46 & 92 & 138 & -316 & -270 & -224 & -178 & -132 & -86 & -46 & 0 \\
\hline & & & & & & $\bar{p}$ & 46 & 46 & 46 & 46 & 46 & 46 & 46 & 46 & 46 & 40 & 46 \\
\hline \multicolumn{7}{|c|}{ Total produced quantity } & 184 & 144 & 178 & 184 & 138 & 138 & 138 & 138 & 138 & 132 & 138 \\
\hline
\end{tabular}

O: Customer Order, P: demanded finished product, Q: demanded quantity, Comp Z: model lateness, Real Z: actual lateness, Imp: Improvement, q:demanded quantity for date $t, s$ : stock for date $t, p$ :produced quantity in date $t$ 
The planning horizon of the MPS is the longest cumulated period of procurement and production. The results in Table II allow therefore, anticipating detailed adjustments of resources, to establish a detailed schedule and to procure orders of raw materials.

\section{CONCLUSIONS}

This paper presents an optimization approach to minimize lateness to deliver customer orders in a make-toorder multi-product assembly line. The results can be exploited as a tool for supporting decision-making in an MPS planning level. Three different dimensions were considered through the proposed optimization problem: 1 . Quantity of production per day for each product, 2. Production scheduling (during the planning horizon), 3. Sequencing (planning inside a given day). Hence, the developed mathematical model results in a master production scheduling for the system studied.

The proposed MILP model has been validated with different sizes of (real-setting) instances. The computational results show a significant reduction in the tardiness of the delivered orders in comparison with the actual delay that results from the current strategy of the company. The development of an approximate solving method for larger instances could be considered as a perspective of this research.

The proposed model has some limitations. First, the maximum number of customer orders included in the planning horizon of 190 working days represents only $20 \%$ of the actual demand. The research group intends to increase the size of the instances in order to ensure more visibility in MPS meetings.

Another limitation comes from the hypothesis of having all of the components and rough materials when starting the production of a customer order. Problems with suppliers, who cannot always deliver on time or according to customer demand, the arrival of new customer orders to be included in the planning horizon, order cancellations or requests on advancing deliveries are external disturbances that have to be managed in the MPS meetings. Further research seeks to use simulations in order to consider the stochastic external disturbances in the model. Internal disturbances like absenteeism and machine breakdowns could also be considered.

A third limitation derives from the number of instances that were employed for studying the computing time. Only three instances were proposed for each product category. In order to better define the behavior of the computational time the construction of more instances, considering a bigger number of orders has been considered for additional research.

Another research perspective is to extend the model by considering other objective functions. The current model could be adapted to maximize capacity utilization. Finally, in order to answer industrial requirements, a future version of the model will consider clients by priority of delivery.

\section{ACKNOWLEDGMENT}

We would like to express our thanks to Exxelia for their support in the development of the present work.

\section{REFERENCES}

[1] Akhoondi, F., and Lotfi, M. (2016) 'A heuristic algorithm for master production scheduling problem with controlable processing times and scenario-based demands'. International Journal of Production Reserch. 54(12), pp. 3659-3676. doi: 10.1080/00207543.2015.1125032

[2] APICS-The Association for Operations Management, 2010. APICS Dictionary. Thirteenth edn. pg. 88. Chicago

[3] APICS The Association for Operations Management, 2011. Basics of Supply Chain Management - Participant Guide Part 1 OF 2, Sessions 1-5.3.2 edn. 3 th section pg. 37 Chicago.

[4] Arnold, J.T., Chapman, S.N. and Clive, L. M. (2008). Introduction to materials Management. 6th edn, Pearson Prentice Hall. 6th edn. Edited by V. R. Anthony and E. Krassow. New Jersey. doi: 10.1017/mdh.2014.75.

[5] Buyurgan, N., and Saygin, C., 'Application of the analytical hierarchy process for real-time scheduling and part routing in advanced manufacturing systems' J. Manuf. Syst. 27 (3), pp. 101-110, 2008 .

[6] Dörmer,J., Günther,H;O. and Gujjula, R. 'Master production scheduling and sequencing at mixed-model assembly lines in the automotive industry'. Flexible Services and Manufacturing Journal, 27(1), pp. 1-29.doi : 10.1007/s10696-013-9173-8

[7] Lalami, I., Frein, Y., Gayon,J.P. 'A model for master production scheduling in automotive powertrain plants: A case study'International Conference on Idustrial Engineering and Systems Management IESM 2015, Seville, Spain, 21-23 octobre. pp.10811090

[8] Li, X., He, D. (2013) Dynamic master Production scheduling for automobile mixed-mode assembly line based on the rates of pay and profit. International Conference of Computation Information SciencesICCS 2013, 21-23 june, Barcelona, Spain. doi: 10.1109/ICCIS.2013.314

[9] Mourtzis, D., and Vlachou,E.(2018) 'A cloud-based cyber-physical system for adaptive shop-floor scheduling and condition-based maintenance' J. Manuf. Syst. 47,pp. 179-198.doi: 10.1016/j.jmsy.2018.05.008

[10] Sahin, F., Robinson,E.P and Gao,L (2008) 'Master production scheduling policy and rolling schedules in a two-stage make-to-order supply chain' International Journal of Production Economy. 115( 2), pp. 528-541. doi: 10.1016/j.ijpe.2008.05.019

[11] Sawik,T. (2007)'Multi-objective master production scheduling in make-to-order manufacturing' International Journal of Production Research.45( 12), pp. 2629-2653. doi: 10.1080/00207540600847152

[12] Vallhagen, J., Almgren, T. and K. Thörnblad, 'Advanced use of Data as an Enabler for Adaptive Production Control using Mathematical Optimization - An Application of Industry 4.0 Principles' in FAIM, 2017, vol. 11, no. June, pp. 663-670.doi: 10.1016/j.promfg.2017.07.165.

[13] Wang, B., Guan, Z., Ullah, S. et al. (2017) 'Simultaneous order scheduling and mixed-model sequencing in assemble-to-order production environment: a multi-objective hybrid artificial bee colony algorithm'. Journal of Intelligent manufacturing, 28 (2), pp. 419-436. doi:10.1007/s10845-014-0988-2 